\title{
ED impact of a mass gathering pre-hospital support system: the Rouen Armada event 2013
}

\author{
Dumouchel $\mathrm{J}^{1}$, Roussel $\mathrm{M}^{1 *}$, Taalba $\mathrm{M}^{1,2}$, Lefevre $\mathrm{A}^{2}$, Joly $\mathrm{LM}^{1}$ and Lvovschi $\mathrm{VE}^{3}$ \\ ${ }^{1}$ Emergency Department, Rouen University Hospital, F-76031, Rouen, France \\ ${ }^{2}$ Department of Anaesthesiology, Intensive Care and Emergency Medical Services (SAMU 76), Rouen University Hospital, Rouen, F-76000, France \\ ${ }^{3}$ Emergency Department, F-76031, Rouen University Hospital, Normandie Univ, UNIROUEN, INSERM U1073, Rouen, France
}

\begin{abstract}
Objective(s): There is no data about the intra-hospital crowding effect of pre-hospital mass gathering support systems. Our objective was to evaluate the impact on emergency departments (EDs) of the Rouen Armada event 2013 (RAE2013), a major French happening.

Methods: We performed a multicenter, observational study based on the prospective collection of data on-site ( 8 first aid stations) and from 5 EDs in the Rouen area.

The main study endpoint was the total number of patients presenting to EDs for an Armada-related reason (ARR). Secondary endpoints were: demographics, care pathways, final diagnosis, care characteristics and outcomes. Then, we performed a focussed analysis on two subgroups (with vs without pre-hospital examination).

Results: Among 1,261 patients examined on-site, 246 presented to ED with an ARR (63\% with accidental injury, 85\% discharged home). Only 6 patients had severe injuries. $88 \%$ of patients required some technical support in the ED. In the subgroup without pre-hospital examination (49\%), we found significantly higher rates of young and local patients, which mainly presented to a private hospital. In the other subgroup, we found a higher significant rate of discomfort and more use of ED technical support (biology, EKG).
\end{abstract}

Conclusions: RAE2013 pre-hospital support system efficiently protected EDs from overcrowding. Most of the ED visits were appropriate. This study highlights the importance of sufficient on-site resources for the most common presentations, and the relevance of intra-hospital registers.

\section{Introduction}

The organization of event medicine is based on disaster medicine regulations [1]. Sporting or cultural events related tragedies led to define on-site care criteria for monitoring and medicalizing largescale events. Mass gathering support systems require knowledge of geographic, climatic, health population density risks [2-5]. The regional care system needs adaptations to preserve the daily medical activities. Each hospital has a preparedness plan for special crowding linked to a mass influx of victims $[5,6]$

Every 4 years in France, Armada event is an international vessel meeting which convenes several million visitors over 11 days along the river Seine, in Rouen city center. It represents a real medical challenge by its size, duration and fluctuating attendance (evening concerts, fireworks ...) with the risk of disrupting the daily health regional care system. Rouen area has 2 adult EDs and 1 pediatric ED at Rouen University Hospital (public care system) and 2 comprehensive private EDs. Medical on-site organization includes: an Emergency Medical Dispatch Center (CRRA) with 2 dedicated physician dispatchers, 8 first aid stations (FASs) based on care providers from several first aid associations as French Red Cross (Figure 1). Only two FASs are fully medicalized with a Mobile Emergency and Resuscitation Unit (SMUR) and a general practitioner. The event site is open around the clock.

For RAE2013, the system was designed according to national [7] and international recommendations [8]. The care providers-patient ratios justified a need for 15 doctors and nurses for 200 patients at FASs, and 50 to 60 first aid responders had to be deployed on site depending on the expected attendance (one additional FAS).
In order to monitor each Armada event, the French Institute for Public Health Surveillance (INVS) perform an epidemiologic study based on the real-time data collection of the various reasons for presenting to FAS, which was primarily designed for daily health alert system $[9,10]$. However, until now there was no monitoring in EDs to adjust diagnosis and outcomes. In addition, there is no model of ED crowding prediction for large-scale events and no previous study on patients who present spontaneously to EDs with event related reasons.

We decided to evaluate the impact of RAE2013 on ED crowding. This study will analyse intra-hospital data in order to evaluate the number and the relevance of ED visits for Armada-related reasons (ARR).

\section{Methods}

A multicenter, prospective observational study was carried out between June 6th and $16^{\text {th }}, 2013$.

We performed two parallel data collections: One conducted in the 8 FASs and one in the 5 EDs of the Rouen area. We focussed on patients

${ }^{\star}$ Correspondence to: M Roussel, Emergency Department, Rouen University Hospital , 1 rue de Germont, 76031 Rouen - Cedex, France, E-mail: melanie. roussel@chu-rouen.fr

Key words: mass gathering; emergency medical service; disaster medicine

Received: April 12, 2019; Accepted: April 25, 2019; Published: April 29, 2019 


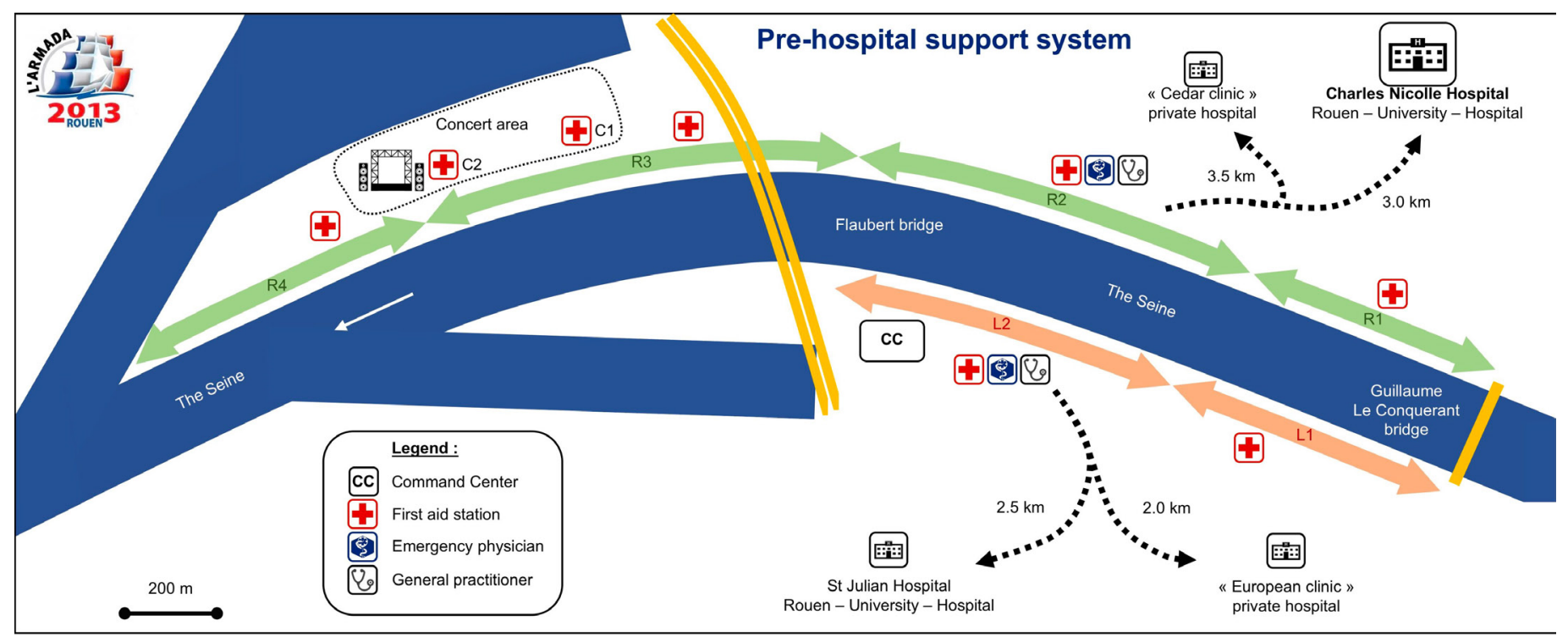

Figure 1. Support system of Rouen Armada 2013

presenting for an Armada-related reason (ARR) in EDs, whatever their on-site pathway.

Moreover, as some patients present spontaneously to the EDs, we compared in a supplementary analysis 2 subgroups of patients, with or without pre-hospital examination, in order to assess if ED visits were more appropriate for those with prior contact to FAS.

We collected all data from CRAA calls and from the 8 FAS examinations under the supervision of French Institute for Public Health Surveillance (INVS), using the 13-item coding grid developed and based on daily surveillance indicators.

In each of the five EDs, patients presenting for an ARR were identified. The same coding grid as used in the FAS was filled in and sent daily to the health monitoring unit. We provided medical records of each patient with sociodemographic characteristics, place of residence, final diagnosis and outcomes (hospitalization or discharge), additional examinations performed and specialized advices requested.

The main end point of the study was to determine the total number of patients presenting to EDs for an ARR.

Secondary end points were to describe the patient's characteristics: demographics, care pathways (reasons for presenting, additional examinations, medical care decisions and outcomes), care characteristics and outcomes. Then we compared in two subgroups of patients (with or without pre-hospital examination in a FAS), the resources used in the EDs as electrocardiogram, biology, imagery, and specialized advices, etc...

\section{Statistical analysis}

Basic descriptive statistics were performed. Qualitative variables are expressed in numbers and percentages and quantitative variables as mean and standard deviation or median and interquartile range (for non normal distributions). The comparison between patients with and without pre-hospital examination was performed for the qualitative variables using the Chi-square test or the exact Fisher test. The odds ratio and its $95 \%$ confidence interval $(95 \%$ CI) was calculated for each of these variables. The mean of the continuous variables was compared using the (parametric) Student test supplemented by a (non parametric)

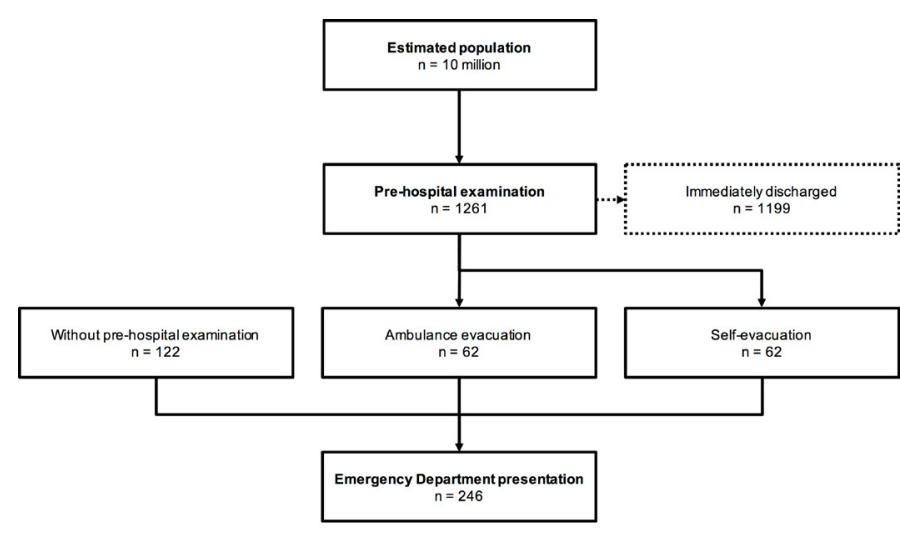

Figure 1. Support system of Rouen Armada 2013

Wilcoxon test. The data analysis was performed using $\mathrm{R}$ software ( $\mathrm{R}$ Development Core Team 2018) with an agreed alpha risk of 5\%.

\section{Ethical considerations}

The study protocol and patient-informed consent procedures have received local Ethics Committee approval (E2019-19), according to the latest version of the Declaration of Helsinki.

\section{Results}

For RAE2013, the number of visitors was estimated between 300,000 and 500,000 per day. The CRAA received a total of 388 emergency calls. 1,261 patients were examined at FASs, from which 124 were sent to the EDs, included 62 ambulance evacuations (Figure 2). One patient was directly transferred to the cardiac intensive care unit (ICU). A peak number of on-site examinations was observed during the 2 weekends with 501 examinations (40\%) on the 2 Saturdays.

At the FASs, 33\% of patients presented for accidental injuries, $16 \%$ for discomfort, $32 \%$ for unspecified reasons and $12 \%$ for alcoholization isolated or not. Pre-hospital examination was performed by a physician for $16 \%$.

In EDs, a total of 246 patients presented for an ARR, (Figure 3). Mean age was 35 years, and $69 \%$ of patients were from the 


\begin{tabular}{|c|c|c|c|c|c|c|c|c|c|}
\hline & \multicolumn{2}{|c|}{ Total } & \multicolumn{2}{|c|}{$\begin{array}{c}\text { With } \\
\text { pre-hospital } \\
\text { examination }\end{array}$} & \multicolumn{2}{|c|}{$\begin{array}{c}\text { Without } \\
\text { pre-hospital } \\
\text { examination }\end{array}$} & \multirow[t]{2}{*}{$\begin{array}{l}\text { Odds ratio } \\
\text { [IC95\%] }\end{array}$} & \multicolumn{2}{|c|}{ P-value } \\
\hline Number of patients & 2 & 6 & 124 & $(50)$ & 122 & (50) & & & \\
\hline Age (years) Median - IQ [25\%-75\%] & 35 & {$[20-57]$} & 45 & [24-64] & 28 & {$[19-48]$} & & $<0.0001$ & $* * * *$ \\
\hline \multicolumn{10}{|l|}{$\operatorname{Sex} n(\%)$} \\
\hline Male & 118 & $(48)$ & 67 & (54) & 51 & $(42)$ & $0.6[0.3-1.1]$ & 0.057 & \\
\hline Female & 128 & $(52)$ & 57 & $(46)$ & 71 & (58) & & & \\
\hline \multicolumn{10}{|l|}{ Residence n (\%) } \\
\hline District & 170 & (69) & 65 & $(52)$ & 105 & (86) & $0.2[0.1-0.3]$ & $<0.0001$ & $* * * *$ \\
\hline France & 65 & $(26)$ & 53 & $(42)$ & 12 & (10) & $6.8[3.3-15]$ & $<0.0001$ & $* * * *$ \\
\hline Other countries & 11 & (4) & 6 & (5) & 5 & (4) & & & \\
\hline \multicolumn{10}{|l|}{ Diagnosis n (\%) } \\
\hline Accidental injury & 156 & (63) & 74 & $(60)$ & 82 & (67) & $0.7[0.4-1.2]$ & 0.24 & \\
\hline Discomfort & 27 & (11) & 20 & (16) & 7 & (6) & $3.1[1.2-9.2]$ & 0.01 & $* *$ \\
\hline Alcoholization & 37 & (15) & 17 & (14) & 20 & (16) & & & \\
\hline Other* & 20 & (8) & 13 & (11) & 7 & (6) & & & \\
\hline Headache & 6 & (2) & 4 & (3) & 2 & (2) & & & \\
\hline Drowning & 4 & (3) & 4 & (3) & 0 & (0) & & & \\
\hline Abdominal symptoms & 10 & (4) & 3 & (2) & 7 & (6) & & & \\
\hline Dyspnea & 8 & (3) & 3 & (2) & 5 & (4) & & & \\
\hline Chest pain & 3 & (1) & 3 & (2) & 0 & (0) & & & \\
\hline Burn injury & 2 & (1) & 1 & $(0.8)$ & 1 & $(0.8)$ & & & \\
\hline \multicolumn{10}{|l|}{ Care n (\%) } \\
\hline Imagery & 124 & $(50)$ & 69 & $(56)$ & 55 & (45) & & & \\
\hline Medicine & 95 & (38) & 51 & (41) & 43 & (35) & & & \\
\hline Biology & 50 & (20) & 37 & $(30)$ & 13 & (11) & $3.5[1.7-7.7]$ & 0.0002 & $* * * *$ \\
\hline EKG & 27 & (11) & 19 & (15) & 8 & (6) & $2,6[1-7,1]$ & 0,04 & $* *$ \\
\hline Suture and immobilization & 43 & (17) & 16 & (13) & 27 & (22) & $0,5[0,2-1,1]$ & 0,06 & \\
\hline No support & 29 & $(12)$ & 13 & (11) & 16 & (13) & & & \\
\hline Short observation & 9 & (4) & 5 & (4) & 4 & (3) & & & \\
\hline Specialist advices & 5 & (2) & 2 & (2) & 3 & (3) & & & \\
\hline \multicolumn{10}{|l|}{ Place of care $n(\%)$} \\
\hline Adult public hospital & 166 & (67) & 94 & (76) & 72 & (59) & $2.2[1.2-3.9]$ & 0.006 & $* * *$ \\
\hline Pediatric public hospital & 32 & (13) & 12 & (10) & 20 & (16) & & & \\
\hline Private hospital & 38 & $(15)$ & 10 & $(8)$ & 28 & (23) & $0.3[0.1-0.7]$ & 0.001 & $* * *$ \\
\hline Intensive care unit & 6 & (2) & 6 & (5) & 0 & (0) & & & \\
\hline General practitioner & 4 & (2) & 2 & (2) & 2 & (2) & & & \\
\hline \multicolumn{10}{|l|}{ Outcomes n (\%) } \\
\hline Discharged home & 209 & $(85)$ & 100 & $(81)$ & 109 & (89) & $0.5[0.2-1.1]$ & 0.07 & \\
\hline Hospitalization & 37 & (15) & 24 & (19) & 13 & (11) & $2[0.9-4.5]$ & 0.07 & \\
\hline Surgery & 20 & (8) & 14 & (11) & 6 & (5) & $2.4[0.8-8.1$ & 0.1 & \\
\hline
\end{tabular}

* Other: Anxiety, otorhinolaryngologic, ophthalmologic or dermatologic problems 
district. $63 \%$ of patients presented with accidental injury, $15 \%$ for alcoholization, $11 \%$ discomfort, and $8 \%$ for minor reasons as anxiety, otorhinolaryngologic, ophthalmologic or dermatologic problems. $85 \%$ were discharged home, six patients were treated for critical presentations: acute coronary syndrome, major discomfort, acute respiratory failure, epilepsy, drowning and alcoholic coma. No patient required intubation or died. Some technical support in the ED was required for $88 \%$ of patients.122 (49\%) ED patients spontaneously presented without pre-hospital examination. They were significantly younger, from the district $(\mathrm{p}<0.0001)$, had significantly less discomfort $(\mathrm{p}=0,01)$ and mainly presented to private EDs $(\mathrm{p}=0.001)$. No statistic differences were found for gender and others medical characteristics and outcomes. Conversely, in the other subgroup with pre-hospital examination, we found a significant higher rate of biology $(p=0,0002)$ and electrocardiograms $(p=0,04)$, but not for the other additional examinations. Adults patients mainly presented at public hospital $(\mathrm{p}=0.006)$.

\section{Discussion}

In this work we evaluated the impact of the RAE2013 support system on the surrounding emergency facilities. Over around 6 million visitors, only 246 patients presented to EDs, with a very low impact on usual EDs organization. As there was no disaster situation, there was normal functioning of the daily cares in the EDs. RAE2013 onsite medical care and optimal management of emergency crowding was guaranteed, with low evacuation rates after examination [11]. The preservation of normal ED functioning should facilitate an easier response to an unexpected disaster situation.

Moreover, most of the ED visits could be considered appropriate, especially when patients had been sent to the ED after pre-hospital examination.

It is obviously difficult to predict the number and characteristics of all patients presenting to ED during mass-gathering events [12-15] with exclusively pre-hospital data.

Many factors influence ED use during mass-gathering events: visitor numbers, demographics, geographic and climatic characteristics, event duration, alcohol delivery [16]. A global risk index [6-9] helped to identify several risks for on-site providers, relevant for RAE2013: proximity to water, fluctuating attendance (fireworks, concerts, etc.), audience type (family, festive), and climate-related risks. Despite the proximity of the river, there were few falls into the water. The weather conditions for the event were favourable: One heat peak was recorded with one related examination peak in FASs.

Data collected on site are mainly health monitoring data (epidemic risk surveillance, etc.), while intra-hospital data reflect patients' real needs. The development of intra-hospital registers, using original traumatologic indicators and outcomes, is necessary to balance prehospital data.

In our study, intra-hospital data showed a large prevalence of minor traumatological presentations. This may be explained by the fact that the event is spread over several kilometers, with visitors walking extensively on cobblestones, promoting accidental injuries (ankle sprains, wounds, lower limb pain, etc.). Therefore, patients presenting to ED mainly required low-level medicalization, with numerous but basic uses of technical support, and little hospitalization.

In most cases, local patients did not seek care on site and presented in private EDs, whereas French tourists presented first to FASs. This could be explained by the difference of knowledge of available hospitals near site. Private facilities are known in the area as less overcrowded. Finally, outcomes were similar, whatever the care patterns. Conversely, in the pre-hospital examination subgroup, we found a significant higher rate of discomfort, blood-tests and electrocardiogramm. These data could be correlated, as the diagnosis evaluation of a discomfort most often requires such additional examinations. We can hypothesis that pre-hospital physician decided to evacuate patients with discomfort in order to use the technical support of the EDs.

Nevertheless, our study has some biases. First, patients which presented to a private physician or to a specialized ED physician (ophthalmology, gynecology) were not included. Second, there were missing data on patient transport modes to ED (30\%) suggesting some medical regulations by the CRAA without data collection. For instance, in the without pre-hospital examination subgroup, at least $40 \%$ of patients were presented by ambulance, without evacuation decision.

Finally, in this double epidemiologic study, we entered and coded data manually. Computerization could be an improvement to promote networking between the different facilities. Coding on site and in EDs would allow the precise and homogeneous analysis of the impact of this kind of event [17]. In addition, the monitoring of an exceptional event with rapid kinetics could be limited by manual data entry (loss of data).

\section{Conclusion}

This original prospective study, focussed on intra-hospital data, shows that the RAE2013 pre-hospital support system had a protective role on ED crowding in the Rouen area. Most ED visits were appropriate, especially when patients had been sent to the ED after pre-hospital examination. Our results assess the importance of having sufficient resources on site to manage the most common presentations, and highlight the relevance of an intra-hospital registry, not based of preventive care system goals, in order to adjust diagnosis and outcomes data. These results will make it possible to anticipate surveillance of the upcoming Rouen Armada events.

\section{Conflicts of Interest}

All authors have no conflict of interest to declare, including financial, consultant, institutional and other relationships that might lead to bias.

\section{Funding}

However, the author VEL discloses that she has received occasional travel grants for participation in national and international congresses from Mundipharma.

\section{Acknowledgements}

We are grateful to Nikki Sabourin-Gibbs for providing medical writing support and editorial assistance.

\section{Authors' contributions}

JD and MT conceived the study design and wrote the manuscript. LMJ is the scientific referent of the study and critically revised the manuscript. MR, ALS and VEL, wrote and revised the final manuscript. All authors have read and approved the final manuscript.

\section{References}

1. WHO (2015) Public health for mass gatherings: key considerations, World Health Organization.apps.who.int/iris/bitstream/10665/162109/1/WHO_HSE_GCR_2015.5_eng.pdf 
2. Locoh-Donou S, Yan G, Berry T, O’Connor R, Sochor M, et al. (2016) Mass gathering medicine: event factors predicting patient presentation rates. Intern Emerg Med 11: 745-752.

3. Lund A, Turris SA, Bowles R, Steenkamp M, Hutton A, et al. (2014) Mass-gathering Health Research Foundational Theory: Part 1-Population Models for Mass Gatherings. Prehospital Disaster Med 29: 648-654.

4. Turris SA, Lund A, Hutton A, Bowles R, Ellerson E, et al. (2014) Mass-gathering Health Research Foundational Theory: Part 2 - Event Modeling for Mass Gatherings. Prehospital Disaster Med 29: 655-663.

5. http://www.samu-urgences-de-france.fr/medias/files/155/794/sudf_1407_reco_ rassemblements.pdf

6. SFMU recommendations (2010) crowd gatherings \& medical event management. Fr Soc Emerg Med.

7. https://www.secourisme.net/IMG/pdf/RNMSC-DPS.pdf

8. http://www.femede.org/docs/REFERENTIELMEDICAL.pdf

9. http://invs.santepubliquefrance.fr/publications/2004/armada_rouen/index.html

10. http://invs.santepubliquefrance.fr/fr/Publications-et-outils/Rapports-et-syntheses/ Populations-et-sante/2014/Bilan-et-evaluation-de-la-surveillance-sanitaire-de-1Armada-de-Rouen-edition-2013
11. Grange JT, Baumann GW, Vaezazizi R (2003) On-site physicians reduce ambulance transports at mass gatherings. Prehosp Emerg Care 7: 322-326.

12. Hartman N, Williamson A, Sojka B, Alibertis K, Sidebottom M, et al. (2009) Predicting resource use at mass gatherings using a simplified stratification scoring model. Am J Emerg Med 27:337-343.

13. Zeitz KM, Zeitz CJ, Arbon P (2005) Forecasting medical work at mass-gathering events: predictive model versus retrospective review. Prehospital Disaster Med 20: 164-168.

14. Arbon P, Bottema M, Zeitz K, Lund A, Turris S, et al. (2018) Nonlinear Modelling for Predicting Patient Presentation Rates for Mass Gatherings. Prehospital Disaster Med 33: 362-367.

15. DeMott JM, Hebert CL, Novak M, Mahmood S, Peksa GD (2018) Characteristics and resource utilization of patients presenting to the ED from mass gathering events. Am J Emerg Med pp. 983-987.

16. Milsten AM, Seaman KG, Liu P, Bissell RA, Maguire BJ (2003) Variables influencing medical usage rates, injury patterns, and levels of care for mass gatherings. Prehospital Disaster Med 18: 334-346.

17. Lund A, Turris SA, Amiri N, Lewis K, Carson M (2012) Mass-gathering medicine: creation of an online event and patient registry. Prehospital Disaster Med 27: 601-611.

Copyright: (C2019 Dumouchel J . This is an open-access article distributed under the terms of the Creative Commons Attribution License, which permits unrestricted use, distribution, and reproduction in any medium, provided the original author and source are credited. 